\title{
Frequency of efficacy of topical cyclosporine $0.05 \%$ eye drops in the management of dry eyes
}

\author{
MUHAMMAD KHALID ${ }^{1}$, MUHAMMAD RIZWAN², SAMEERA KHURSHID ${ }^{3}$ \\ ${ }^{1}$ Professor, Department of Ophthalmology, Sahiwal Medical College Sahiwal \\ ${ }^{2}$ Assistant Professor, Department of Ophthalmology, Sahiwal Medical College Sahiwal \\ ${ }^{3}$ Assistant Professor, Bahawalpur College of Pharmacy, Bahawalpur \\ Correspondence to Dr. Muhammad Khalid, Email: Khalidvision@hotmail.com, Cell: 03017730748
}

\begin{abstract}
Aim: To determine the efficacy of cyclosporine $0.05 \%$ for the management of patients of dry-eye disease presenting at tertiary care hospital.

Methods: This cross sectional study was conducted at Department of Ophthalmology, Sahiwal Medical College, Sahiwal from March 2020 to September 2020 over the period of 6 months. Total 310 patients of dry eye were included in this study after scrutinized by inclusion criteria. All the selected patients were managed with cyclosporine $0.05 \%$ and efficacy of the drug was assessed.

Results: Total 310 patients of dry eye disease were recruited. Mean age was $47.15 \pm 3.61$ years and mean duration of dry eye disease was $11.10 \pm 1.75$ months. Out of 310 patients, treatment was found effective in 225 $(73 \%)$ patients. Efficacy of treatment was noted in $172(96.63 \%)$ male patients and in $53(40.15 \%)$ female patients. Significantly higher rate of efficacy was noted in male patients as compared to female patients with $p$ value 0.000 . Conclusion: Results of present study showed higher improvement rate of dry eye symptoms in cases of dry eye managed with cyclosporine $0.05 \%$. Male patients were more victim of dry eye as compared to female patients and statistically significant association of efficacy with gender was observed. No association of efficacy of treatment with age group and duration of disease was observed.

Keywords: Dry eye, cyclosporine, inflammation, immunomodulator agents.
\end{abstract}

\section{INTRODUCTION}

Among ocular morbidities, dry eye (DE) is very common. ${ }^{1}$ Ocular pain, foreign body sensation, sense of dryness and burning are linked with DE. Visual fatigue, blurred vision and photophobia are sometimes associated with DE. ${ }^{2}$ Pathogenesis of Dry eye has not been completely clarified. Many clinical and pathological changes affecting tear film, lacrimal glands, and eyelids with resulting deficiency in the tear film whether caused by decreased lacrimation or excessive evaporation. ${ }^{3}$ Cells of ocular surface, including inflammatory, epithelial, immune and goblet cells may play a main role in the pathogenesis of DE. ${ }^{4}$ Many studies propose new concepts of its pathogenesis, including that DE seems to be caused by inflammation mediated by T-cell lymphocytes. ${ }^{5}$ In cases of $\mathrm{DE}$, disorder of cytokine balance, increased osmolarity, decreased tear volume and increased matrix metalloproteinases can be seen commonly. It is observed that apoptosis and inflammation might be play a major role in theprogression or development of DE. ${ }^{6}$ Anti-inflammatory treatments like corticosteroids and topical cyclosporine were recommended for the management of DE. ${ }^{7}$ There is a link between long time uses of topical corticosteroids and development of cataracts, glaucoma and some other side effects related to use of steroid. In contrast, topical cyclosporine, which specifically blocks T-cell activation, may be a more appropriate long-term therapy because it is not associated with either significant systemic adverse events or the common steroid-related ocular side effects. ${ }^{8}$

The purpose of the study is to decrease frequency of topical eye dropings from two hourly with other treatment

Received on 13-01-2021
Accepted on 23-05-2021

modalities to 8 hourly with cyclosporin $0.05 \%$, treat ocular surface disease and reduce the inflammation which is the root cause of dry eye thus reducing morbidity of disease. OPERATIONAL DEFINITION

Efficacy: Defined as: when any 2 out of three tests was negative.

Tear break up time

Negative: tear breakup time $>10$ seconds.

Rose Bengal staining:

Negative: if there is no staining:

Schirmer's tests:

Negative: wetting of filter paper $>5 \mathrm{~mm}$.

\section{MATERIAL AND METHODS}

This cross sectional study was conducted at Department of Ophthalmology,Sahiwal Medical College, Sahiwal from March 2020 to September 2020 over the period of 6 months. Total 310 patients of dry eye either male or female having age 30-70 years were included in this study after scrutinized by inclusion criteria. Patients with history of ocular allergic disease, patients with history of pterygium, patients with history of previous refractive surgery, patients with systemic connective tissue disease, patients with active ocular disease and patients with prior use of topical cyclosporine were excluded from the study.

Patient's history was taken and 3 tests (tear break up time, rose Bengal staining test and Schirmer's tests) were performed on all selected patients for diagnosis of dry eye.

Cyclosporine $0.05 \%$ drops was prescribed to all the selected patients for 3 months. Efficacy (Yes/No) was measured by re-evaluating all the patients which were 
prescribed Cyclosporine $0.05 \%$ drops previously by applying 3 tests.

Data was entered on computer software SPSS version 16. The quantitative variables of the study i.e. age, duration of symptoms were presented as Mean $\pm S D$. The qualitative variables like gender and frequency of efficacy was presented as frequency and percentages. Pie chart was drawn for frequency of efficacy. Stratification was done for age, gender and duration of symptoms. Post stratification chi-square test was applied. $P$ value $\leq 0.05$ was considered as significance.

\section{RESULTS}

Total 310 patients of dry eye disease were recruited. Mean age was $47.15 \pm 3.61$ years and mean duration of dry eye disease was $11.10 \pm 1.75$ months. Out of 310 patients, treatment was found effective in 225 (73\%) patients. (Fig. 1) Age range was $30-70$ years. Two age groups $30-50$ years and $51-70$ years were created. In 30-50 years age group, there were 190 (61.29\%) patients and in age group $51-70$ years, there were $120(38.71 \%)$ patients. Treatment was found effective in $136(71.58 \%)$ patients of age group $30-50$ years and in 89 (74.17\%) patients of age group 5170 years. There was insignificant association between efficacy of treatment and age group with $p$ value 0.619 . (Table 1)Male patients were 178 (57.42\%) and female patients were 132 (42.58\%). Efficacy of treatment was noted in $172(96.63 \%)$ male patients and in $53(40.15 \%)$ female patients. Significantly higher rate of efficacy was noted in male patients as compared to female patients with $\mathrm{p}$ value 0.000 . (Table 2 )
Duration of dry eye disease was 1-6 months. Patients were divided into two groups according to duration of disease i.e. 1-3 months and 4-6 months. Out of 151 (48.71\%) patients of 1-3 months group, efficacy was found in 109 (72.19\%) patients. In 4-6 months group, treatment was found effective in 116 (72.96\%) patients. Statistically insignificant association between efficacy and duration of disease was noted with $p$ value 0.879 . (Table 3 )

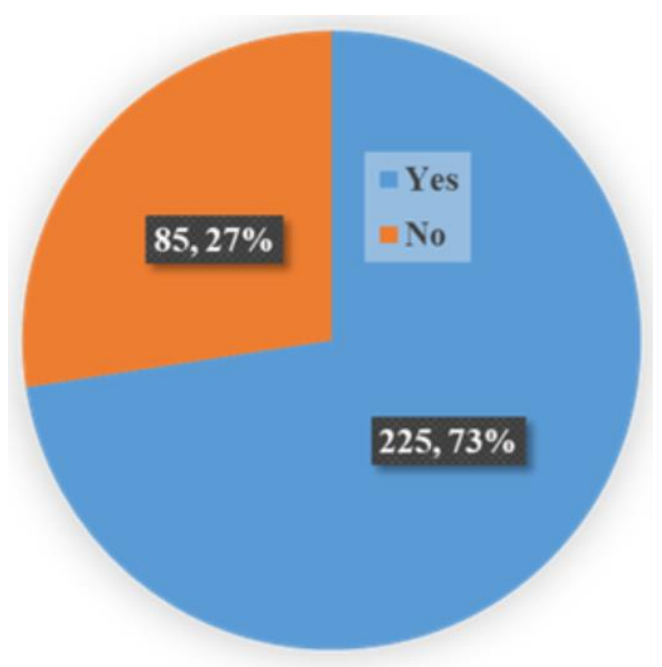

Fig. 1: Frequency of efficacy

Table 1: Stratification for age

\begin{tabular}{|l|c|c|c|c|}
\hline \multirow{2}{*}{ Age Group } & \multicolumn{2}{|c|}{ Efficacy } & Total & \multirow{2}{*}{ P value } \\
\cline { 2 - 4 } & Yes & No & $190(61.29 \%)$ & \multirow{2}{*}{0.619} \\
\hline $30-50$ & $136(71.58 \%)$ & $54(28.42 \%)$ & $120(38.71 \%)$ & \\
\hline Total & $89(74.17 \%)$ & $31(25.83 \%)$ & 310 & \\
\hline
\end{tabular}

Table 2: Stratification for gender

\begin{tabular}{|l|c|c|c|c|}
\hline \multirow{2}{*}{ Gender } & \multicolumn{2}{|c|}{ Efficacy } & \multirow{2}{*}{ Total } & \multirow{2}{*}{ P value } \\
\cline { 2 - 4 } & Yes & No & $178(57.42 \%)$ & \multirow{2}{*}{0.00} \\
\hline Male & $172(96.63 \%)$ & $6(3.37 \%)$ & $132(42.58 \%)$ & \\
\hline Total & $53(40.15 \%)$ & $79(59.85 \%)$ & 310 & \\
\hline
\end{tabular}

Table 3: Stratification for duration of disease

\begin{tabular}{|l|c|c|c|c|}
\hline \multirow{2}{*}{$\begin{array}{l}\text { Duration of disease } \\
\text { (months) }\end{array}$} & \multicolumn{2}{|c|}{ Efficacy } & Total & \multirow{2}{*}{ P value } \\
\cline { 1 - 4 } & Yes & No & $151(48.71 \%)$ & \multirow{2}{*}{0.879} \\
\hline $4-6$ & $109(72.19 \%)$ & $42(27.81 \%)$ & $159(51.29 \%)$ & \\
\hline Total & $116(72.96 \%)$ & $43(27.04 \%)$ & 310 & \\
\hline
\end{tabular}

\section{DISCUSSION}

Dry eye is a very common disease. In United States, among the patients of dry eye having age over 65 years, $25 \%$ of the patients used artificial tears. Ocular irritation was faced by 7.1 million people of USA, about $6 \%$ population of $4^{\text {th }}$ decade of life and about $15 \%$ population of $6^{\text {th }}$ decade of life faced dry eye syndrome. ${ }^{9}$ The purpose of the present study was to determine the efficacy of cyclosporine $0.05 \%$ in the management of dry-eye disease.
Total 310 patients of dry eye disease were recruited in this study. Mean age was $47.15 \pm 3.61$ years and mean duration of dry eye disease was $11.10 \pm 1.75$ months. Out of 310 patients, treatment was found effective in 225 (73\%) patients. In 30-50 years age group, there were 190 $(61.29 \%)$ patients and in age group $51-70$ years, there were $120(38.71 \%)$ patients. Treatment was found effective in $136(71.58 \%)$ patients of age group 30-50 years and in $89(74.17 \%)$ patients of age group 51-70 years. There was insignificant association between efficacy of 
treatment and age group with $p$ value 0.619 .In one study by Byun et $a l,{ }^{10}$ after three months using of Cyclosporine $0.05 \%$ in cases of DE, efficacy of treatment was noted in $72 \%$ patients which is in accordance with our study. In study ofAl-Nashar et al, ${ }^{11}$ total 20 patients of dry eye were selected and managed with cyclosporine $0.05 \%$ eye drops. In this study age of the patients was between 26-65 years with mean age 37.3 years. In all patients ocular symptoms was significantly improved with treatment of cyclosporine $0.05 \%$ eye drops after three months. Prabhasawat et $\mathrm{al}^{12}$ managed 30 cases of dry eyes with cyclosporine $0.05 \%$ eye drops. Out of 30 patients, only 17 patients completed the study and 8 patients withdrew due to intolerable side effects cyclosporine $0.05 \%$ and 5 cases lost follow up. Over all efficacy of treatment was $72.1 \%$. In present study male patients were $178(57.42 \%)$ and female patients were 132 (42.58\%). Efficacy of treatment was noted in 172 $(96.63 \%)$ male patients in $53(40.15 \%)$ female patients. Significantly higher rate of efficacy was noted in male patients as compared to female patients with $p$ value 0.000 .In study of Mah et al, $^{13}$ total 35 patients were managed with cyclosporine $0.05 \%$ eye drops, most $(71.4 \%)$ of the patients were female and treatment was found effective in $80 \%$ patients. Byunet $\mathrm{al}^{14}$ found significant improvement in cases of dry eye managed with cyclosporine $0.05 \%$.In study ofRao et al, ${ }^{15}$ dry eye patients were managed with cyclosporine $0.05 \%$ and treatment was found effective in $68 \%$ patients.

\section{CONCLUSION}

Results of present study showed higher improvement rate of dry eye symptoms in cases of dry eye treated with cyclosporine $0.05 \%$. Male patients were more victim of dry eye as compared to female patients and statistically significant association of treatment efficacy with gender was observed. No association of efficacy of treatment with age group and duration of disease was observed.

\section{REFERENCES}

1. O'Brien PD, Collum LMT. Dry eye: diagnosis and current treatment strategies. Curr Allergy Asthma Rep. 2004 Jul;4(4):314-9.

2. Zoukhri D. Effect of inflammation on lacrimal gland function. Exp Eye Res 2006;82:8 85-898.
3. Conrady CD, Joos ZP, Patel BCK. Review: The lacrimal gland and its role in dry eye. J Ophthalmol [Internet]. 2016 [cited 2017 Apr 15];2016. Available from: http://www.ncbi.nlm.nih.gov/pmc/articles/PMC4793137/

4. Barabino S, Chen Y, Chauhan S, Dana R. Ocular surface immunity: homeostatic mechanisms and their disruption in dry eye disease. ProgRetin Eye Res. 2012 May;31(3):27185.

5. Bhavsar AS, Bhavsar SG, Jain SM. A review on recent advances in dry eye: pathogenesis and management. Oman J Ophthalmol. 2011;4(2):50-6.

6. Wei Y, Asbell PA. The core mechanism of dry eye disease (ded) is inflammation. Eye Contact Lens. 2014 Jul;40(4):248-56.

7. Stonecipher KG, Chia J, Onyenwenyi A, Villanueva L, Hollander DA. Health claims database study of cyclosporine ophthalmic emulsion treatment patterns in dry eye patients. TherClin Risk Manag. 2013;9:409-15.

8. Schultz C, Schultz C. Safety and efficacy of cyclosporine in the treatment of chronic dry eye. Ophthalmology and Eye Diseases. 2014 Jun;37.

9. Kymionis GD, Bouzoukis DI, Diakonis VF, Siganos C. Treatment of chronic dry eye: focus on cyclosporine. Clinical Ophthalmology (Auckland, NZ). 2008 Dec;2(4):829.

10. Byun YS, Rho CR, Cho K, Choi JA, Na KS, Joo CK. Cyclosporine $0.05 \%$ ophthalmic emulsion for dry eye in Korea: a prospective, multicenter, open-label, surveillance study. Korean Journal of Ophthalmology. 2011 Dec 1;25(6):369-74.

11. Al-Nashar HY. Efficacy of topical cyclosporine $0.05 \%$ eye drops in the treatment of dry eyes. J Egypt OphthalmolSoc 2015;108:233-6.

12. Perry HD, Solomon R, Donnenfeld ED, Perry AR, Wittpenn $J R$, Greenman HE, Savage HE. Evaluation of topical cyclosporine for the treatment of dry eye disease. Archives of Ophthalmology. 2008 Aug 11;126(8):1046-50.

13. Mah F, Milner M, Yiu S, Donnenfeld E, Conway TM, Hollander DA. PERSIST: Physician's Evaluation of Restasis $\AA$ Satisfaction in Second Trial of topical cyclosporine ophthalmic emulsion $0.05 \%$ for dry eye: a retrospective review. Clinical ophthalmology (Auckland, NZ). 2012;6:1971.

14. Byun YS, Jeon EJ, Chung SK. Clinical effect of cyclosporine $0.05 \%$ eye drops in dry eye syndrome patients. Journal of the Korean Ophthalmological Society. 2008 Oct 1;49(10):1583-8.

15. Rao SN. Topical cyclosporine $0.05 \%$ for the prevention of dry eye disease progression. Journal of Ocular Pharmacology and Therapeutics. 2010 Apr 1;26(2):157-64. 